\title{
Analysis of the Cultural Education in Korean Language Teaching
}

\author{
Honglian Zhang
}

Foreign Languages College, Beihua University, Jilin, 132013, China

Keywords: Cultural education, Korean language teaching, Korean culture

\begin{abstract}
The introduction of cultural elements is an important part of language teaching. In Korean teaching, reasonable and effective permeation of Korean culture elements is an important method to train students' language learning and application abilities. This paper analyzes the main contents of the cultural education in Korean language teaching, and puts forward some Korean education suggestions, such as making cultural comparison, improving cultural experience and utilizing cultural resources to provide some references for the relative researchers.
\end{abstract}

\section{Introduction}

South Korea is an important neighbor of our country, and trade between the two countries is closely related. In recent years, with the development of global economic integration, a Korean fever has come into being in china. At present, China has hundreds of colleges and universities opened a Korean professional, but with Korean vogue, the defects of China's higher education in the construction of teachers' team, cultural infiltration and teaching conditions have also been highlighted. Therefore, how to improve the students' practical ability in Korean, and realize the free communication between Korean and Korean people, is the key problem that colleges and universities are facing. Language and culture are closely related. Language embodies social culture and social culture is integrated into language. Therefore, in the process of learning language, we must fully understand the social culture of the language. At the same time, language is not only a means of communication, but also embodies a nation, a nation's character, values, habits and ways of thinking, if left the culture, the language will lose its connotation. Therefore, in the Korean language teaching in our universities, teachers must fully integrate culture and language, so that students can develop language learning in a particular cultural environment. And then improve students' language ability and communication ability, cultivate students' cross-cultural awareness, and can use language to communicate effectively with people. If the language learning left the cultural penetration, so learning just stay on the surface, it is difficult for students to people with different cultural background for effective and accurate communication, is very unfavorable to improve the students' comprehensive ability of using language. In the Korean language teaching, there is no reasonable and scientific introduction of cultural factors, which fundamentally affects the efficiency of learning and the improvement of learning level, and hinders the further development of Korean teaching. Therefore, in order to fundamentally improve this situation, we must pay attention to the cultivation of Korean cultural consciousness and the introduction of cultural elements.

\section{Main Content of Cultural Education in Korean Language Teaching}

Korean Diet Culture. Koreans are seated by age. Eat on the Kang, a man sitting cross legged woman erected right knee. This method is only limited to wear hanbok sitting at. Eat with chopsticks, soup with a spoon, and chopsticks and spoons cannot be placed on the bowl and plate, to be placed on the table. Eating order: left for the right hand under the table, pick up the spoon, drinking water from the pickled cabbage soup spoon and then drink a soup, eat a meal, they can be free to eat anything. 
When eating, the elders do not move chopsticks, who cannot move, and the elders do not move dishes, and cannot move, after dinner, the elders did not leave the seat first, others cannot move. Share the food on your plate and eat later. The vinegar and the chili sauce are best served on the plate. A bone or fishbone that cannot be eaten while eating, avoiding others, quietly wrapped in paper, thrown away, and not on the table or on the floor. When eating, coughing or sneezing, remove your face and cover your mouth with your hand or handkerchief, so as not to be impolite. Don't eat too fast and don't be too slow. Pace yourself with others. When you eat with your elders, wait for your elders to put down the spoon and chopsticks before putting them down. After dinner, spoon and chopsticks are placed in the initial position, and used napkins are folded up and placed on the table. When using toothpicks, use one hand to cover them. After using them, throw them away before others see them. In the banquet according to the status, position and seniority or in wine, a tall toast first, the others follow in turn. A right hand put the bottle, the left hand holds the bottle bottom, to bow, speech is higher, senior wine, for three people do not drink the cup.

Korean Costume Culture. T Hanbok is the evolution from the ancient to the modern nation of Korean traditional dress, elegant and tasteful, is a traditional Korean dress, South Korea is one of the excellent traditional culture. The characteristics of traditional Korean Costume "hanbok" fusion line and soft curve. Women's dresses consist of short skirts and loose skirts. They are very elegant. Men's clothes are made of coats and trousers, and coats and hats show off the beauty of their clothes. As white people, the basic color is white hanbok. According to different seasons, different identities, their clothing, clothing, cloth, colors are different. In case of marriage and other special days, civilians wearing nobles wear hanbok gorgeous colors and decorations, wedding dress red dress by a deepening pink jacket, topped with a shawl. The cape is composed of five kinds of color gorgeous clothes, this is a reference to the east of the five elements. The recent emergence of fusion hanbok advantages and add a modified hanbok practical domestic. In Korea, when a child is one year old, there is a ceremony to pray for children who have no disease or long life. At this point, the child should wear one year old clothes. The boys wear light colored clothes, blue pink edge is generally short, shallow purple trousers, wearing a blue vest top, green belt. With dark green or yellow jacket for girls. Hanbok is characterized by color, texture, decoration and other casual. Use more than two colors, beyond the scope of pure color, affected by Yin and Yang, five lines of thought. Edge decoration patterns, but also adds beauty hanbok. Hanbok can according to the identity, function, gender, age, purpose, material classification. In modern point of view, the use of the distinction between the most representative. According to the custom of living purposes, hanbok is divided into wedding dress, holiday clothing, clothing and other age. The traditional wedding dress wedding hanbok gorgeous than usual.

Korean Social Culture. In Korea, socializing is a culture that people pay more attention to, and the social etiquette of Koreans is very particular. Korean advocating Confucianism, respect for elders, elders came into the room, everyone should stand up, asked them well. Take off sunglasses when talking to the elders. Get up in the morning and after dinner to greet their parents; parents go back, the children have to meet others to eat. You should give way to the elderly when you take the bus. Dinner should be as old or older rice dishes. You should give way to the elderly when you take the bus. The degree of bowing when Koreans meet to show respect. When you meet and greet in China, look for respect, usually nodding or shaking hands. Nowadays, when meeting Korean officials, they can shake hands or gently nod their heads. Women generally do not shake hands with people. In Chinese culture, bow used in performances, weddings or alumni ceremony, thanks or humility, or apologize. In addition, in South Korea, students sent General legs down, hands above his head. But in China, punishing each other is never letting the other person kneel. Kneel down is only for parents or kings, in addition, kneel in China, usually insulting behavior. Moreover, in South Korea, are dating the man for the first time to the woman's home, often to the woman's parents worship ceremony in the Chinese kneel, no culture. Koreans don't show their feelings easily; public places don't talk and laugh loudly. Especially when women laugh, they also use handkerchiefs to cover their mouths, so as to avoid making rude remarks. In South Korea, women respect men very much. When they meet, women 
always bow to men first and greet them with regards. When men and women are together, men are often on the seat, while women are in the lower seats.

\section{Permeation Methods of Cultural Education in Korean Language Teaching}

Make Cultural Comparison. Contrast the cultural differences between China and Korea, and deepen the students' understanding of Korean culture. Although China and South Korea have similar human geography, the culture of the two countries is unique. The introduction in Korean language teaching with cultural elements, can be compared with the China culture of Korean culture, make the students feel the Chinese and Korean cultural similarities and differences, deepen students' understanding of Korean culture and master. Pay attention to the cultural contrast between the contrast is the key way to carry out Chinese teaching, different language and culture, way of expression is not the same, by contrast can help students find out cultural and structural differences between the target language and the mother tongue, and sensitivity to language. The teacher should make the students understand the cultural differences between China and Korea in the cultural infiltration, and then form the ability to respond to language. Through the contrast of cultural introduction, can promote students' mother tongue interference elimination, deepen students' understanding of Korean culture, respect the Korean historical traditions and customs, to realize the harmonious communication, free communication purposes. Again, to simulate the creation of culture communication situations, teachers in the classroom teaching, carefully created and design with rich Korean culture communicative situations for students, and organize students to communicate in specific situations, improve students' language competence and intercultural awareness. Students often make mistakes in Korean conversation, which is due to the cultural background, social role and emotional personality of both sides in the communication situation. Therefore, from the teaching of the cultural environment and social environment, it cannot effectively improve the students' comprehensive ability to use Korean. Through the creation of scenarios, students can be exposed to different situations and experience different situations of culture and language. In the process of Korean teaching, the first is to abandon the traditional misconceptions about cultural factors, and to recognize the importance of cultural factors in Korean language learning. In the teaching concept, teachers should pay attention to the introduction of cultural elements, and establish an open and interactive modern teaching concept. This is the basic prerequisite for the rational and effective introduction of cultural elements.

Improve Cultural Experience. In the traditional Korean education, the teacher is just mechanical and overly systematic about Korean pronunciation, vocabulary, grammar and other basic knowledge, without considering and paying attention to students' practical ability. In the Korean language teaching strategies, to cultivate students' practical ability, promote the active participation of students willing to explore Korean teaching course, through the course of participation and inquiry, clear Korean cultural elements play an important role in Korean education. Found the problem with China's cultural differences in the use of the Korean language practice, and textual research on the further understanding of the master Korean cultural elements, enhance the awareness and understanding of Korean culture, so as to promote the upgrading of the level of Korean. Teachers should organize students to carry out drama, in pairs, panel discussions and role-playing activities to encourage students to actively participate in the activities, the use of Korean bold practice exchanges, and strengthen students' comprehensive ability in Korean. In the introduction of South Korea folk culture, game culture, teachers simply explain the name of the game and the origin, and the rules of the game, the game can be used to prepare in advance, on-site to teach students how to play the game, let the students play the game. After the game, let the students talk about the feelings of playing games in Korean, or simply explain the rules of the game. In short, in the Korean language class, let students understand and can experience Korean culture education activities, such activities should be arranged in a comprehensive way to improve listening, speaking, reading and writing ability as the goal. Cultural experience can enliven the atmosphere of teaching and deepen students' understanding and memory of knowledge. Although the classroom is an important way to carry out Korean learning, 
but classroom teaching alone cannot achieve a deep level of cultural education. Therefore, in order to effectively complement to classroom teaching, teachers should actively guide students in extra-curricular reading Korean newspapers and magazines and literary works, the teacher can also recommend students to Korean website, get the latest information in South Korea by browsing the web, realizing knowledge with the times.

Utilize Cultural Resources. With the development of multimedia technology in education, it has provided more teaching resources for Korean culture infiltration. Through the multimedia technology can create a rich environment of Korean culture for students, bring students the most vivid and latest cultural and linguistic information, and through the visual understanding of the body, facial expression and gestures nonverbal interaction. Teachers can use multimedia courseware, slides, Internet, TV, movies and other forms, for students to show about Korean culture's voice, image and video, give the students a real cultural experience, and then let the students fully understand the local customs and practices, Korean social history and culture. Through pictures or videos, the cultural education that students can see and feel with their own eyes can attract more attention and interest of the students than the cultural explanation that the teacher explains and explains, and the teaching effect is more effective. For example, when talked about the Korean folk culture to the students, first put some drama in the masked dance scene, and then to introduce students to the origin of Korean folk culture and culture content. Architecture, clothing, diet and so on, preferably with pictures or videos to show. Teachers can also compare the differences between Korean culture and their own country in terms of cultural content, and train students' personal thinking about culture. In the process of teaching, language teachers can make use of modern teaching facilities such as computers to broaden their horizons. The use of multimedia teaching, to appreciate the Korean language teaching materials and cultural elements of information, using multimedia technology to show in three-dimensional form, increasing the interest of Korean language teaching. It allows students to feel more immersive, the charm of Korean language and culture, and enrich the students' feelings about Korean and culture. Teachers should also encourage students to watch more documentaries about Korean cultural backgrounds to encourage students to appreciate Korean culture in a relaxed and varied environment, and to enhance their appreciation and appreciation. At the same time, teachers should organize extracurricular activities, to provide students with the opportunity to contact the South Korean culture, such as South Korea held a movie review, Korean drama, dance contest, speech contest and debate competition and knowledge competition, through the competition to carry out the Korean culture for students' penetration.

\section{Conclusion}

Language and culture are closely related. Language is an important form of culture and culture is the development source of language. Therefore, in Korean learning, it is necessary to introduce cultural elements into the teaching. The Permeation Methods of Cultural Education in Korean Language Teaching can train excellent language talents to provide important guarantee for the exchange and cooperation between China and Korea.

\section{References}

[1] Su Xiaoxia. On the Cultural Educationin in Teaching Korean Language [J]. Journal of Huaihai Institute of Technology (Humanities \& Social Sciences Edition), 2013, 11(23): 81-83.

[2] Zhao Fengzhu, Sun Yingshan. Lack of local culture in translation: a study of the Chinese translation of the TV plays of the Republic of Korea [J]. Journal of Yunnan Minzu University (Social Sciences), 2014, 31(4): 150-155.

[3] Zhang Haiqin. A Tentative Study on Korean Culture of Language Mapping from the Angle of Korean Teaching [J]. Journal of Educational Institute of Jilin Province, 2012, 28(10): 129-130.

[4] Zhang Guoqiang. Culture Inputs in Korean Language Teaching [J]. Contemporary Korea, 2011(3): 91-98. 